\title{
Bioceutical Properties of Culinary Herbs, Spices and Their Possible Outcomes with Standard Antibiotics
}

\author{
Aneela Mehboob* (1), Ambreen Rafique, Tanveer Abbas \\ Department of Microbiology, University of Karachi, Karachi, Pakistan \\ Email: *aneelamehboob21@outlook.com, taabbas@uok.edu.pk, ambreen.rafique@duhs.edu.pk
}

How to cite this paper: Mehboob, A., Rafique, A. and Abbas, T. (2021) Bioceutical Properties of Culinary Herbs, Spices and Their Possible Outcomes with Standard Antibiotics. Food and Nutrition Sciences, 12, 262-276.

https://doi.org/10.4236/fns.2021.123021

Received: December 29, 2020

Accepted: March 21, 2021

Published: March 24, 2021

Copyright $\odot 2021$ by author(s) and Scientific Research Publishing Inc. This work is licensed under the Creative Commons Attribution International License (CC BY 4.0).

http://creativecommons.org/licenses/by/4.0/

\begin{abstract}
Culinary condiments have been used for centuries to treat several types of ailments. Four ethanolic lipid fractions including Nigella sativa, Foeniculum vulgare, Laurus nobilis, and Coriandrum sativum were selected to assess their antimicrobial potential alone and combined with antibiotics. Antibacterial activity was determined by various conventional procedures such as aromatogram test, well diffusion, macro-broth dilution, disc diffusion assay. The tested lipid fractions exhibited antibacterial activity against selected bacterial strains. Antibacterial activity of lipid fractions was also seen within two hours of incubation. These lipid fractions attacked the cell wall i.e. the penetrability of bacterial cell and hence intracellular contents released in the environment which was detected at $260 \mathrm{~nm}$ of absorbance and verified via scanning electron microscopy. Antagonistic effect was mostly found by the combination of antibiotics and lipid fractions. Though, synergistic effect was obtained with beta-lactam drugs when combined with lipid fraction of Laurus nobilis. Hence the lipid fractions may be used to treat various communicable diseases. However antagonistic outcomes of the combinations suggested that herbal and allopathic therapies should not consume concurrently.
\end{abstract}

\section{Keywords}

Antagonism, Synergism, Antibiotics, Lipid Fractions, Antimicrobial Activity

\section{Introduction}

Lipid fractions (LFs) have been utilized for a considerable length of time for the treatment of human beings. They produce positive therapeutic, restorative and mental impact on human body. These fragrant plants have multiple uses and were considered as the core part of witchcraft, healing and holy practice in Egypt 
[1].

Food associated illnesses are of great concern. Not only foodborne pathogens but commensal microorganisms are huge menace to public health therefore, cannot be neglected. Studies affirmed that commensal bacteria transfer resistance genes to other bacteria faster than pathogenic microbes [2] [3]. Such commensal species for example Citrobacter can easily affect the respiratory tract, enter the circulatory system, upset digestion and cause gastric-related problems like gastroenteritis caused by verotoxigenic $C$. freundii recouped from butter parsley sandwiches [4] [5]. Likewise, Serratia was additionally viewed as innocuous for humans [6]. But later the contribution of Serratia in histamine-producing foodborne poisoning was discovered [7]. Most of the bacteria of Enterobacteriaceae family have enzyme named histidine decarboxylase responsible for histamine production which mounts various allergic responses [8] [9].

On account of enormous expansion of resistance developed against antimicrobial agents, high dose of antibiotics and SOS drugs (last resort) are given to treat infections. These two possible options for recovery are responsible for serious side effects and sometimes produce irreversible damage to the body. Therefore, to consider the consumer's choice towards natural remedy over synthetic drugs which cause minimum to no after effects. Researchers are paying more attention to nature's blessing in the avatar of LFs that possess several benefits and have great antimicrobial potential. LFs used in this research were Laurus nobilis, Foeniculum vulgarae, Coriandrum sativum, and Nigella sativa that possessed remarkable antimicrobial and antioxidant activities [10]. Their activities have never been tested against commensal strains. These commensal strains were recovered from street foods of Karachi city and had a great potential to transfer resistant genes to the pathogenic microbes [11]. The focus of the research was to assess the antimicrobial potential of selected lipid fractions against bacterial strains isolated from street foods, Karachi, and to analyze the possible outcomes produced by the combination of lipid fractions and antibiotics.

\section{Materials and Methods}

\subsection{Tested Microorganisms}

Four gram negative and one gram positive bacterial strains namely Serratia liquefaciens, Serratia fonticola, Escherichia coli, Citrobacter freundii and Staphylococcus aureus respectively were selected. These tested microorganisms were recovered from street foods vended in the city of Karachi [11].

\subsection{Lipid Fractions}

Four ethanolic lipid fractions namely Nigella sativa (black cumin), Coriander sativum (coriander), Foeniculum vulgare (fennel), and Laurus nobilis (bay leaf) were selected to assess their antimicrobial potential against selected strains [12]. These lipid fractions were collected from Food Science and Technology, University of Karachi by solvent extraction procedure [13]. 


\subsection{Aromatogram Test}

Volumetric measurement was performed to find out the direct correlation between LFs and antibacterial activity against selected food borne bacteria. 18 hour's old cultures were standardized in physiological saline and matched with 0.5 concentration of McFarland index. $100 \mu \mathrm{L}$ bacterial inoculum was added and make thin and uniform bacterial lawn on Mueller Hinton agar plates with the help of sterile cotton swabs. Five sterilized filter paper disc of $0.6 \mathrm{~cm}$ soaked in $0.5,1,2,5$, and $7.5 \mu \mathrm{L}$ concentrations of LFs were positioned onto MHA plates and incubated at $37^{\circ} \mathrm{C}$ for $18-24$ hours. Next day observed zone of inhibition around each disc [14] [15] [16].

\subsection{Drop Agar Diffusion Method}

This assay was used to examine the antibacterial activity of four ethanolic LFs in their concentrated form [17] [18]. The Mueller Hinton agar plates were formerly inoculated with test organisms with $0.5 \mathrm{McF}$ arland concentration. $10 \mu \mathrm{L}$ drop of LFs was placed on MHA plates and left untouched for proper dispersion at ambient temperature. After a while, plates were incubated at $37^{\circ} \mathrm{C} \pm 11^{\circ} \mathrm{C}$ for 24 hours. Zone of inhibition around each drop was measured in millimeters.

\subsection{Agar Well Diffusion Method}

Antibacterial activity of ethanolic LFs at different concentrations $(1000 \mu \mathrm{g} / \mathrm{mL}, 500$ $\mu \mathrm{g} / \mathrm{mL}$, and $250 \mu \mathrm{g} / \mathrm{mL}$ ) prepared in DMSO was determined by agar well diffusion method as described by Martins et al., 2013 and Mehboob et al., 2020. To analyze the combined effects of ethanolic LFs were also evaluated by this method [2] [19].

\subsection{Broth Dilution Method}

To determine the minimal inhibitory concentrations of ethanolic lipid fractions in liquid media, broth dilution method was performed as described Weerakkody et al., 2010 at selected concentrations e.g. 1000, 500, 250, 125, 62.5, and 15.625 $\mu \mathrm{g} / \mathrm{mL}$ prepared in DMSO Antibacterial activity of ethanolic lipid fractions based on the occurrence and absence of bacterial growth in the form of turbidity [2] [20] [21].

\subsection{Loss of Absorbance}

To measure the intracellular contents released from bacterial cell, loss of absorbance was estimated at $260 \mathrm{~nm}$ [22]. Working bacterial culture was centrifuged at 13,000 rpm for 15 minutes. $3 \mathrm{x}$ washing was done and cells were transferred to phosphate buffer saline. The concentrations of LFs used were same as broth dilution method and supplemented in bacterial cell suspension. Tested and control tubes were incubated for 2 hours in shaking incubator (CBM-Scientific.ES.20) at $150 \mathrm{rpm}$ with incubation temperature $35^{\circ} \mathrm{C} \pm 2^{\circ} \mathrm{C}$. 2 hours later, $2 \mathrm{~mL}$ samples were filter sterilized by $0.2 \mu \mathrm{m}$ pore sized filter membrane (Sigma Aldrich). The absorbance of the filtrate was measured at $260 \mathrm{~nm}$ via UV-V spectrophotometer Shimadzu, Japan 1240 Mini. 


\subsection{Antibiotics}

Levofloxacin $(5 \mu \mathrm{g})$, streptomycin $(10 \mu \mathrm{g})$, gentamicin $(10 \mu \mathrm{g})$, amoxicillin (10 $\mu \mathrm{g})$, tetracycline $(30 \mu \mathrm{g})$ chloramphenicol $(30 \mu \mathrm{g})$, and oxacillin $(1 \mu \mathrm{g})$. The following antibiotics were purchased from Thermo Fischer Scientific Oxoid Ltd.

\subsection{Scanning Electron Microscopy}

Scanning electron microscopy was performed with JEOL from Japan (model\# JSM-6380) located at Centralized Science Laboratories, University of Karachi. Fresh culture of selected strains of Escherichia coli and Staphylococcus aureus (18 hrs. old) were standardized with $0.5 \mathrm{McF}$ arland index. $10 \mu \mathrm{l}$ of each selected bacterial suspension was inoculated into the micro centrifuge tube containing Mueller Hinton broth and MIC of LFs and incubated at $37^{\circ} \mathrm{C}$ for 18 hours. Control tubes having bacterial suspension were also run alongside. After overnight incubation, $10 \mu \mathrm{L}$ crystal violet was added in microcentrifuge tubes and let it stand for 1 minute. The tubes were centrifuged at 11,000 rpm for 10 minutes. After 3 washes with ethanol at $70 \%, 80 \%$, and $90 \%$, the specimens (bacterial cells) were coated up to $300 \mathrm{~A}^{\circ}$ with gold using smart coater with an ion sputtering device (model JFC-1500) and energy dispersive X-ray spectroscopy detector (model EX-54175JMU; JEOL, Tokyo, Japan). Finally, morphological alterations in the bacterial cell before and after treatment were observed under scanning electron microscope.

\subsection{Evaluation of the Combined Impact of Ethanolic Lipid Fractions and Standard Antibiotics}

According to the method proposed by Moussaoui \& Alaoui, 2016 \& Toroglu, 2007 combined effects of selected ethanolic LFs and antibiotics were examined through disc diffusion method [23] [24]. $10 \mu \mathrm{L}$ drop of undiluted LFs were soaked on promptly accessible antibiotics disc, then plates were permitted to dry for proper diffusion, incubated at $37^{\circ} \mathrm{C} \pm 1^{\circ} \mathrm{C}$ for 24 hours to find out the zone of clearance around each circle. The gained results were differentiated and tabulated between antibiotics + LFs and antibiotics alone by similar strategy as disk diffusion method.

\subsection{Statistical Analysis}

For statistical evaluation, post hoc Duncan test was applied to find out the significant difference at $\mathrm{p}<0.05$ between control and tested sets of ethanolic LFs. All the tests were performed 3 times and results were presented as Mean \pm SD by using SPSS software (version 24, SPSS Inc., USA).

\section{Results}

\subsection{Aromatogram Test}

All the four selected ethanolic LFs demonstrated no antibacterial activity at 0.5 , $1,2,5$, and $7.5 \mu \mathrm{l}$ against all the tested bacterial strains. 


\subsection{Drop Agar Diffusion Method}

Antimicrobial strength of concentrated ethanolic LFs was clearly explained with the aid of drop agar diffusion method. LF of FE exhibited significant antibacterial activity against all the tested bacteria and produced highest zone of inhibition ranges in between $(11 \pm 0$ to $29.66 \pm 0.57) \mathrm{mm}$ among all the selected lipid fractions. Followed by LF of CE gave good competition and secured second position producing inhibition zone between $(9 \pm 0$ to $24.33 \pm 1.15) \mathrm{mm}$. While moderate antibacterial activity showed by LF of LE against all the tested bacterial isolates. However, LF of NE failed to retard the multiplication of $S$. fonticola, and $C$. freundii but demonstrated average antibacterial activity against $E$. coli, $S$. liquefaciens, and $S$. aureus with inhibition zone $(9.93 \pm 0.11) \mathrm{mm},(8.25 \pm 0.4) \mathrm{mm}$, and $(15 \pm 0) \mathrm{mm}$ respectively.

\subsection{Agar Well Diffusion Method}

Antibacterial strength was also determined by agar well diffusion method (Table 1). All four ethanolic lipid fractions failed to inhibit the growth of $S$. fonticola and $S$. liquefaciens at all the chosen concentrations. While all of the lipid fractions showed antimicrobial potential against $S$. aureus and $C$. freundii. The lowest MIC of LF of NE and LE against $S$. aureus and $C$. freundii were $250 \mu \mathrm{g} / \mathrm{mL}$. Correspondingly, the growth of $S$. aureus was inhibited by the LF of FE and CE at $1000 \mu \mathrm{g} / \mathrm{mL}$. The MIC values of FE and CE were $500 \mu \mathrm{g} / \mathrm{mL}$ against $C$. freundii as shown in Table 2.

Table 1. Antibacterial activity of ethanolic lipid fractions of Nigella sativa, Foeniculum vulgare, Coriandrum sativum, and Laurus nobilis by agar well diffusion method ${ }^{\mathrm{a}}$.

\begin{tabular}{|c|c|c|c|c|c|c|c|c|c|c|c|c|}
\hline Bacteria & \multicolumn{3}{|c|}{ Nigella sativa } & \multicolumn{3}{|c|}{ Foeniculum vulgare } & \multicolumn{3}{|c|}{ Coriandrum sativum, } & \multicolumn{3}{|c|}{ Laurus nobilis } \\
\hline \multicolumn{13}{|c|}{ Essential oils concentration in $(\mu \mathrm{g} / \mathrm{mL})$} \\
\hline \multicolumn{13}{|c|}{ Zone of inhibition in $\mathrm{mm}$} \\
\hline & 1000 & 500 & 250 & 1000 & 500 & 250 & 1000 & 500 & 250 & 1000 & 500 & 250 \\
\hline E. coli & $11.53 \pm 0.80$ & $10.4 \pm 0.52$ & $9.13 \pm 0.80$ & $\mathrm{~N} / \mathrm{D}$ & $\mathrm{N} / \mathrm{D}$ & $\mathrm{N} / \mathrm{D}$ & $\mathrm{N} / \mathrm{D}$ & $\mathrm{N} / \mathrm{D}$ & $\mathrm{N} / \mathrm{D}$ & $\mathrm{N} / \mathrm{D}$ & $\mathrm{N} / \mathrm{D}$ & $\mathrm{N} / \mathrm{D}$ \\
\hline S. fonticola & $\mathrm{N} / \mathrm{D}$ & $\mathrm{N} / \mathrm{D}$ & $\mathrm{N} / \mathrm{D}$ & $\mathrm{N} / \mathrm{D}$ & $\mathrm{N} / \mathrm{D}$ & $\mathrm{N} / \mathrm{D}$ & $\mathrm{N} / \mathrm{D}$ & $\mathrm{N} / \mathrm{D}$ & $\mathrm{N} / \mathrm{D}$ & $\mathrm{N} / \mathrm{D}$ & $\mathrm{N} / \mathrm{D}$ & $\mathrm{N} / \mathrm{D}$ \\
\hline S. liquefaciens & $\mathrm{N} / \mathrm{D}$ & $\mathrm{N} / \mathrm{D}$ & $\mathrm{N} / \mathrm{D}$ & $\mathrm{N} / \mathrm{D}$ & $\mathrm{N} / \mathrm{D}$ & $\mathrm{N} / \mathrm{D}$ & $\mathrm{N} / \mathrm{D}$ & $\mathrm{N} / \mathrm{D}$ & $\mathrm{N} / \mathrm{D}$ & $\mathrm{N} / \mathrm{D}$ & $\mathrm{N} / \mathrm{D}$ & $\mathrm{N} / \mathrm{D}$ \\
\hline S. aureus & $12.53 \pm 1.50$ & $9.67 \pm 0.58$ & $8.67 \pm 0.58$ & $8.73 \pm 0.30$ & $\mathrm{~N} / \mathrm{D}$ & $\mathrm{N} / \mathrm{D}$ & $9.5 \pm 0.5$ & $\mathrm{~N} / \mathrm{D}$ & $\mathrm{N} / \mathrm{D}$ & $10 \pm 1$ & $9.4 \pm 0.527$ & $.27 \pm 0.64$ \\
\hline C. freundii & $11.33 \pm 1.15$ & $10.6 \pm 0.52$ & $9.33 \pm 0.58$ & $12.67 \pm 3.21$ & $83 \pm 0.29$ & $\mathrm{~N} / \mathrm{D}$ & $19.33 \pm 0.58$ & $9.6 \pm 0.69$ & $\mathrm{~N} / \mathrm{D}$ & $11 \pm 1.01$ & $11 \pm 1.73$ & $10 \pm 0$ \\
\hline
\end{tabular}

${ }^{a} \mathrm{~N} / \mathrm{D}$ No detection of antibacterial activity. Values are means of triplicates \pm SD.

Table 2. Minimum Inhibitory concentration determined by agar well diffusion method ${ }^{\mathrm{a}}$.

\begin{tabular}{ccccc}
\hline \multirow{2}{*}{ Bacterial strains } & \multicolumn{3}{c}{ MIC of Essential oils $(\mu \mathrm{g} / \mathrm{mL})$} \\
\cline { 2 - 5 } & Nigella sativa & Foeniculum vulgare & Coriandrum sativum & Laurus nobilis \\
\hline E. coli & 250 & N/D & N/D & N/D \\
S. fonticola & N/D & N/D & N/D & N/D \\
S. liquefaciens & N/D & N/D & N/D & N/D \\
S. aureus & 250 & 1000 & 1000 & 250 \\
C. freundii & 250 & 500 & 500 & 250 \\
\hline
\end{tabular}

${ }^{\mathrm{a}} \mathrm{N} / \mathrm{D}=$ No detection of antibacterial activity. 


\subsection{MIC of Lipid Fractions in Broth Dilution Method}

In comparison to the well diffusion results, ethanolic lipid fractions demonstrated and produced enhanced antibacterial potential was detected in broth dilution method (Table 3). The highest and lowest MIC values of LF of FE were $1000 \mu \mathrm{g} / \mathrm{mL}$ for $S$. fonticola and $125 \mu \mathrm{g} / \mathrm{mL}$ for $S$. aureus, E. coli, and S. liquefaciens respectively. The least MIC value of LF of LE detected at $62.5 \mu \mathrm{g} / \mathrm{mL}$ against all the tested bacterial strains except $C$. freundii. Likewise, $125 \mu \mathrm{g} / \mathrm{mL}$ MIC value of LF of NE was noted against $E$. coli, $S$. liquefaciens, $S$. aureus, and $C$. freundii but for $S$. fonticola, $125 \mu \mathrm{g} / \mathrm{mL}$ MIC was observed. Furthermore, the MIC values of $S$. liquefaciens and $S$. fonticola were $500 \mu \mathrm{g} / \mathrm{mL}$ and $125 \mu \mathrm{g} / \mathrm{mL}$ against $S$. aureus and $C$. freundii while no activity was detected against $E$. coli.

\subsection{Loss of Absorbance}

Antimicrobial activity of lipid fractions was significant in broth medium therefore, antimicrobial potential was evaluated by estimating loss of absorbance at $260 \mathrm{~nm}$. All the chosen LFs demonstrated significant difference between the tested and control group. The values were noted after 2 hours of incubation period. All four LFs specifically NE and FE at all the selected concentrations exhibited tremendous activity against $S$. aureus. The highly effected LFs were NE and CE against E. coli at $500 \mu \mathrm{g} / \mathrm{mL}$. Similarly, highest destruction of bacterial cells of $S$. liquefaciens noted at $1000 \mu \mathrm{g} / \mathrm{mL}$ of CE. In case of $S$. fonticola, LF of NE at $250 \mu \mathrm{g} / \mathrm{mL}, \mathrm{LE}$ at $500 \mu \mathrm{g} / \mathrm{mL}, \mathrm{FE}$ at $1000 \mu \mathrm{g} / \mathrm{mL}$ and $500 \mu \mathrm{g} / \mathrm{mL}$ produced irreversible destruction to the bacterial cells. While LFs of NE, CE, and FE were effective against $C$. freundii at $1000 \mu \mathrm{g} / \mathrm{mL}$, and $500 \mu \mathrm{g} / \mathrm{mL}$ respectively (Table 4).

\subsection{Combined Effects}

Combined effects of standard antibiotics and ethanolic LFs were evaluated [25]. All the selected ethanolic LFs produced antagonistic effect against the tested food isolates when combined with selected antibiotics (Tables 5-8). Only LF of L. nobilis (LE) showed synergistic effect when combined with oxacillin and amoxicillin against $C$. freundii in Table 7. Also, synergistic effect was seen against $S$. liquefaciens when combination of LF of $N$. sativa (NE) and levofloxacin applied (Table 8).

Selected LFs combined to determine the antimicrobial strength against five tested food isolates. Noticeable antibacterial activity was not found against any bacterial strains at selected concentrations as demonstrated in Table 9. However, all the possible combination of ethanolic LFs proved significant activity against $S$. aureus with zone of inhibition ranges between $(10 \pm 0$ to $15 \pm 0) \mathrm{mm}$. Among them the most noteworthy and the minimal inhibition zone produced with the blend of $\mathrm{N}+\mathrm{L}$ and $\mathrm{F}+\mathrm{L}$ respectively.

\subsection{Detection of Cellular Alterations}

Significant morphological and physiological changes appeared on bacterial cells after treated with ethanolic LFs. Cell wall became disrupted and it will lead to 
enhance the permeability of cell membrane. Due to increase in permeability, phenomena of cytolysis were seen and cell became swollen up and burst and all the internal contents released outside the cell (Figure 1).

\section{Discussion}

Plants are the great and natural source of obtaining substances that can be used to develop or recreate new germicidal agents. These natural substances have superlative properties alone and in combination and can facilitate the therapeutic process and increase the effectiveness of treatments. To achieve this objective, In vitro examinations are required to find the potentials and competency of natural substances [26]. Antibacterial activity of four ethanolic LFs and their combined impact with commercial drug showed in tables and figure against five food borne isolates. All four ethanolic LFs demonstrated exquisite effects in together agar well and macro-broth techniques. However, some of the LFs unable to show their full antibacterial competency on solid medium as compared to broth medium. This is because of the indirect relation of viscosity and diffusive nature of

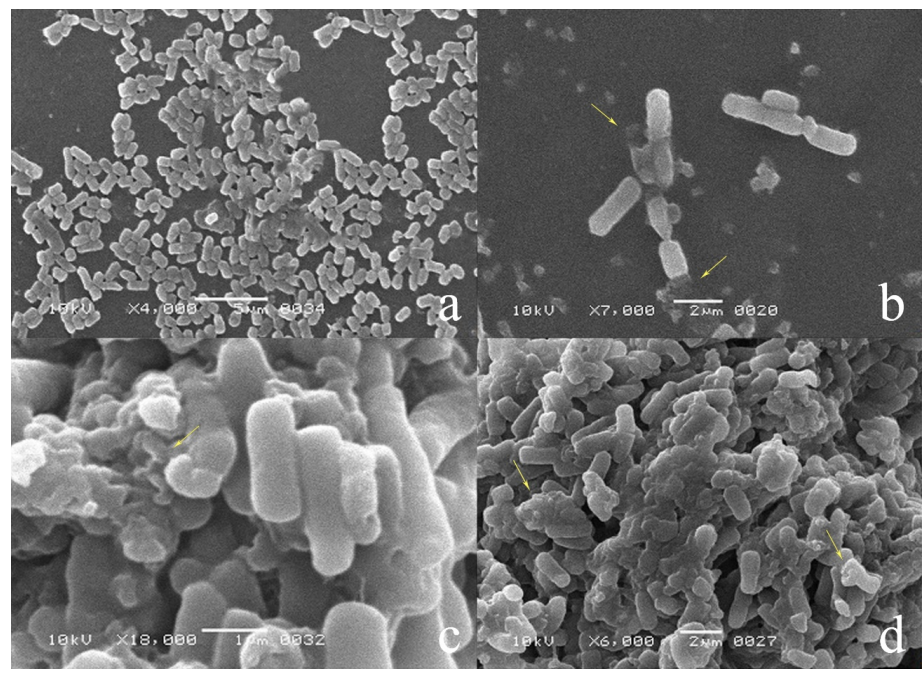

Figure 1. Scanning electron microscopic images of tested bacteria when treated with lipid fractions. Escherichia coli (a) control (b) treated with Nigella sativa at $250 \mu \mathrm{g} / \mathrm{mL}$

(c) Foeniculum vulgare at $250 \mu \mathrm{g} / \mathrm{mL}$; (d) treated with Laurus nobilis at $250 \mu \mathrm{g} / \mathrm{mL}$.

Table 3. Minimum Inhibitory concentration determined by broth dilution method ${ }^{\mathrm{a}}$.

\begin{tabular}{ccccc}
\hline \multirow{2}{*}{ Bacterial strains } & \multicolumn{3}{c}{ MIC of Essential oils $(\mu \mathrm{g} / \mathrm{mL})$} \\
\cline { 2 - 5 } & Nigella sativa & Foeniculum vulgare & Coriandrum sativum & Laurus nobilis \\
\hline E. coli & 125 & 125 & N/D & 62.5 \\
S. fonticola & 62.5 & 1000 & 500 & 62.5 \\
S. liquefaciens & 125 & 125 & 500 & 62.5 \\
S. aureus & 125 & 1000 & 125 & 62.5 \\
C. freundii & 125 & 125 & 125 & 125 \\
\hline
\end{tabular}

${ }^{a} \mathrm{~N} / \mathrm{D}=$ No detection of antibacterial activity. 

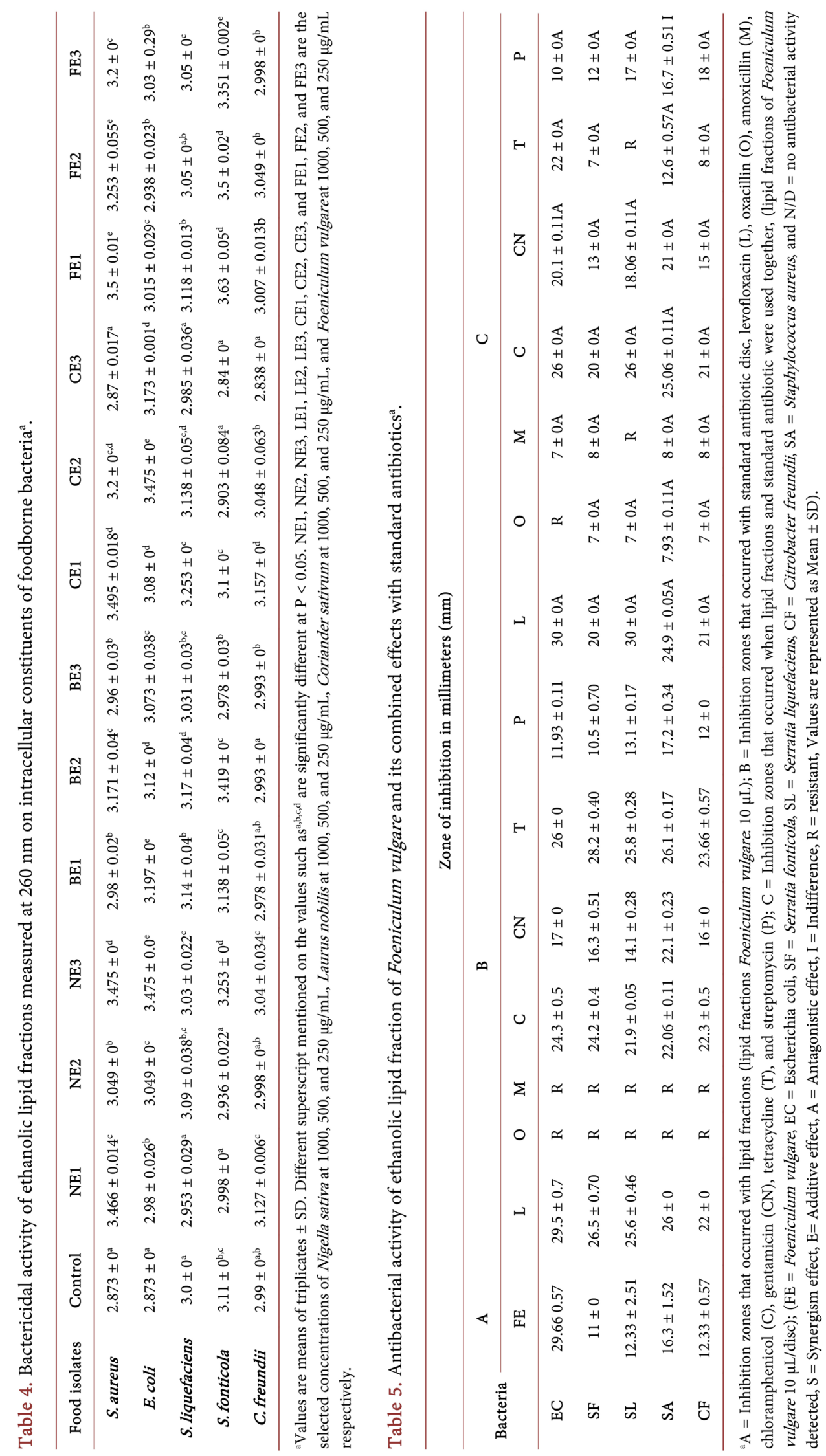


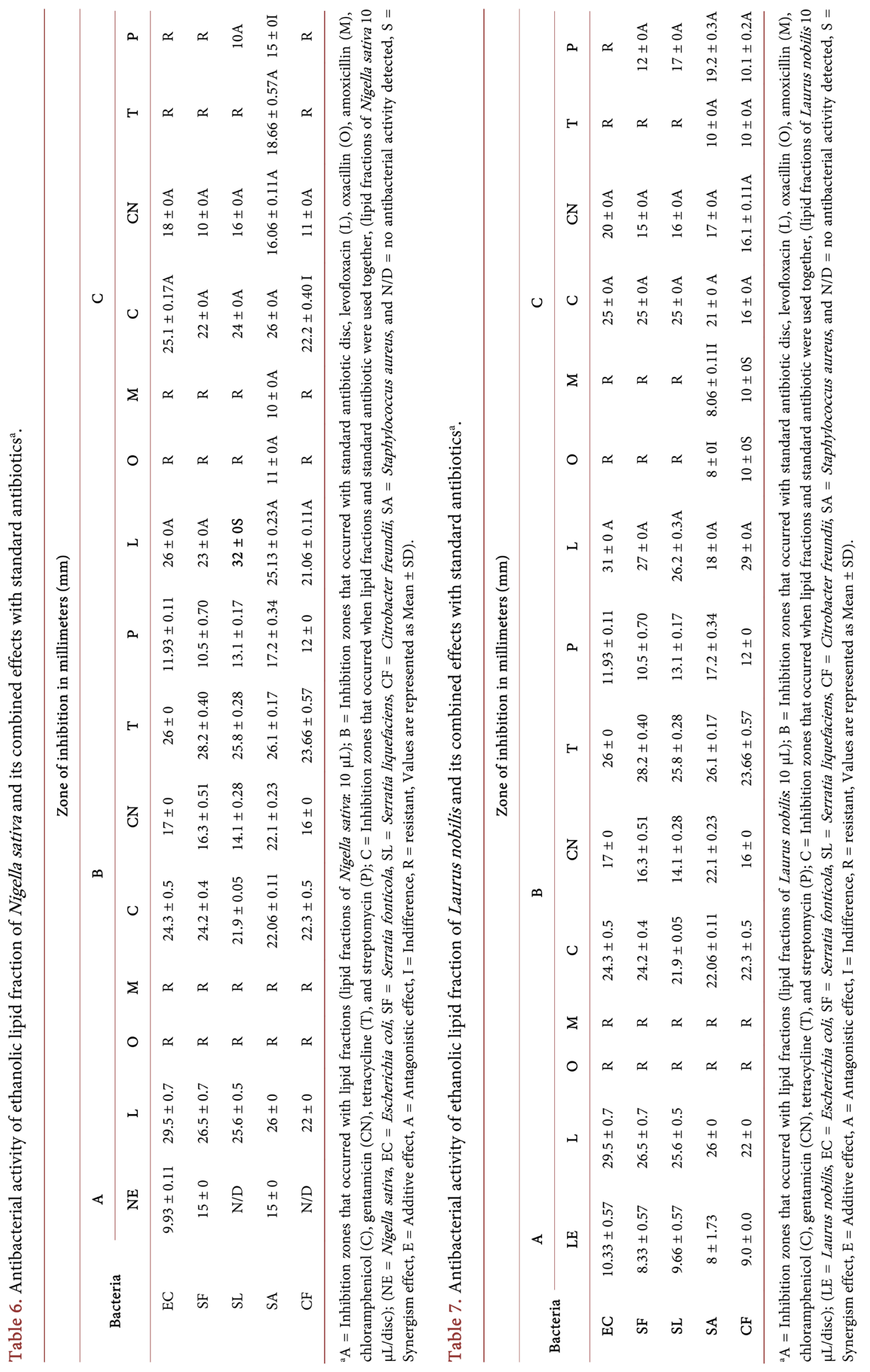




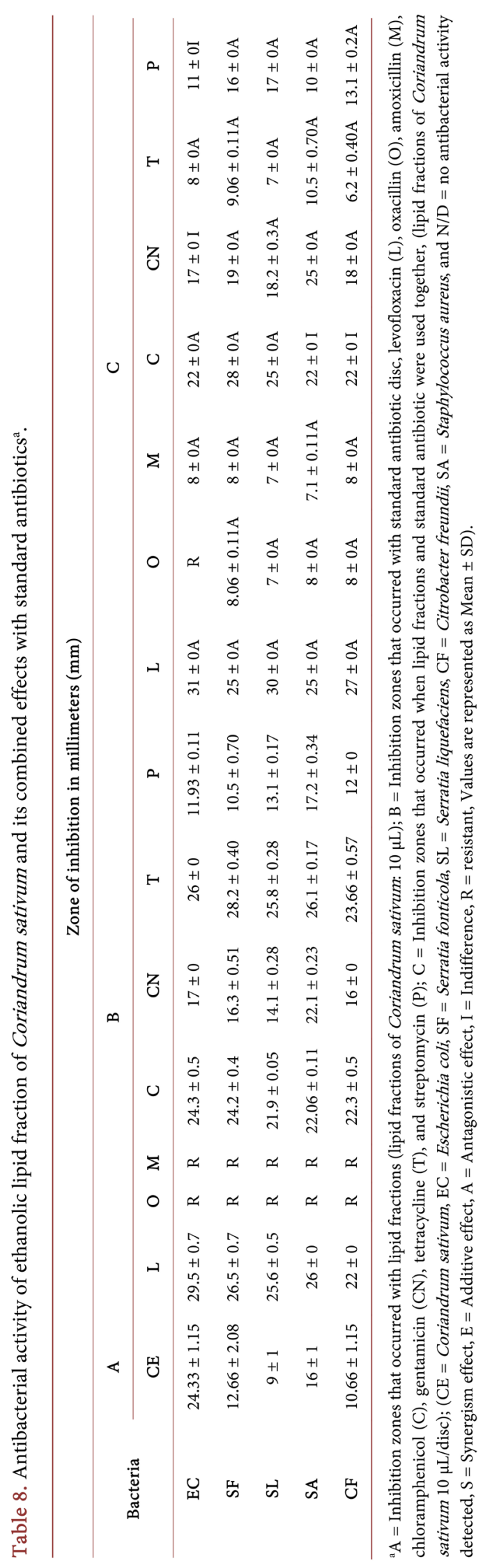


Table 9. Antibacterial activity of combined effects of ethanolic lipid fractions by agar well diffusion method ${ }^{\mathrm{a}}$.

\begin{tabular}{cccccc}
\hline & \multicolumn{5}{c}{ Bacterial strains } \\
LFs conc. & \multicolumn{5}{c}{ Zone of inhibition in millimeter (mm) } \\
\cline { 2 - 6 } & E. coli & C. freundii & S. liquefaciens & S. aureus & S. fonticola \\
\hline N + F & N/D & N/D & N/D & $12.8 \pm 0.01$ & N/D \\
N + L & N/D & N/D & N/D & $15 \pm 0$ & N/D \\
N + C & N/D & N/D & N/D & $10.04 \pm 0.3$ & N/D \\
F + L & N/D & N/D & N/D & $10 \pm 0$ & N/D \\
F + C & N/D & N/D & N/D & $13 \pm 0.01$ & $14.2 \pm 0.04$ \\
L + C & N/D & N/D & N/D & N/D
\end{tabular}

${ }^{\mathrm{a}} \mathrm{N} / \mathrm{D}=\mathrm{No}$ antibacterial activity detected; $\mathrm{N}+\mathrm{F}=($ Nigella sativa + Foeniculum vulgare $) ; \mathrm{N}+\mathrm{B}=($ Nigella sativa + Laurus nobilis $) ; \mathrm{N}+\mathrm{C}=($ Nigella sativa + Coriandrum sativum $) ; \mathrm{F}+\mathrm{L}=($ Foeniculum vulgare + Laurus nobilis $) ; \mathrm{F}+\mathrm{C}=($ Foeniculum vulgare + Coriandrum sativum $) ;$ and $\mathrm{L}+\mathrm{C}=($ Laurus nobilis + Coriandrum sativum); conc. $=$ concentrations.

LFs. Higher the thickness of LFs, the less it diffused through agar medium [27]. The least MIC was noted at $62.5 \mu \mathrm{g} / \mathrm{ml}$ in macro-broth dilution method. Among all, LF of $L$. nobilis produced antibacterial effects at $62.5 \mu \mathrm{g} / \mathrm{ml}$ towards the selected foodborne strains except $C$. freundii at $125 \mu \mathrm{g} / \mathrm{ml}$. Therefore, it could be hypothesized that ethanolic LFs are very compatible in Mueller Hinton broth and demonstrate their antibacterial potentials at their best [10].

Synergistic effects were only seen against $S$. aureus with the combination of LF of $N$. sativa and levofloxacin and secondly against $C$. freundii, when the combination of $L$. nobilis and oxacillin and amoxicillin were applied. While rest of the possible combinations exhibited inhibitory results. Therefore, it could be proposed that ethanol may have a negative impact and block the interaction of LFs and antibiotics. Natural compounds of plants and drugs interacted in same pharmacodynamics manner as drugs interacted with each other. Four different outcomes usually appeared when drug-drug interaction occurred in laboratory examination namely synergistic, indifference, additive, and antagonistic [28]. Several studies have reported the synergistic and other effects produced by the interactions of plants produced compounds and drugs [29] [30] [31]. Plants released natural substances made up of the mixture of various bioactive components. These bioactive components attach to the active spot present on the bacterial cell that determine the antimicrobial strength of substance and their effectiveness rely on the synchronous action of these functional groups present in the natural substances [32] [33].

Phenomena of synergism can be seen in the condition when two different compounds attack pathogen by using different mechanisms. While additive effect was observed when two different compounds attack the pathogen with same mechanism. For example, mode of action of one compound is cell wall inhibition and other is to stop protein synthesis. One of the study reported that the combined effect of vancomycin (cell wall inhibitor) and the extract of Canarium odontophyllum produced additive results because the mode of action of $\mathrm{CO}$ was 
the same as the drug (vancomycin) [33] [34].

Such practice is adapted by various laboratory technologists and researchers to reduce the expansion of drug resistance. Secondary metabolites produced by plants have broad spectrum antimicrobial activity with minimum side effects. Therefore, they could be a perfect alternative of artificial medicines. On the other hand, the blend of natural metabolites with commercial drugs might regain the effectiveness of existing medicine that is lost due to over exploitation. Thus, the interaction of new antimicrobials and the synthetic drugs that produce synergistic and additive outcomes could ease the process and duration of treatment [35].

\section{Conclusion}

This research pinpoints the idea of utilizing LFs for therapeutic purpose. Ethanolic lipid fractions were phenomenal and exhibited great effort to kill and inhibit the growth of microbes. These natural constituents prove to be a good substitute of synthetic drug. Further studies are required to purify those compounds, responsible for antimicrobial activity. Unfortunately, antagonistic outcomes were found by the combination of antibiotics and LFs could suggest the idea that both allopathic and herbal treatment should not take simultaneously. However, synergistic effect was also observed with beta-lactam drugs.

\section{Acknowledgements}

The author desires to express her gratefulness to Ms. Ayeza Naeem for providing lipid fractions from Department of Food Science and Technology, University of Karachi.

\section{Conflicts of Interest}

The authors declare no conflicts of interest regarding the publication of this paper.

\section{References}

[1] Tisserand, R. (1988) Essential Oils as Psychotherapeutic Agents. In: Perfumery, Springer, Dordrecht, 167-181. https://doi.org/10.1007/978-94-017-2558-3 9

[2] Mehboob, A. and Abbas, T. (2020) Synergistic Effect of the Combination of Commercial Essential Oils with Standard Antibiotics: In Vitro Evaluation. Biological Sciences, 63, 242-252.

[3] Paterson, D.L. (2006) Resistance in Gram-Negative Bacteria: Enterobacteriaceae. American Journal of Infection Control, 34, S20-S28. https://doi.org/10.1016/j.ajic.2006.05.238

[4] Drelichman, V. and Band, J.D. (1985) Bacteremias Due to Citrobacter diversus and Citrobacter freundii: Incidence, Risk Factors, and Clinical Outcome. Archives of Internal Medicine, 145, 1808-1810. https://doi.org/10.1001/archinte.145.10.1808

[5] Tschäpe, H., Prager, R., Streckel, W., Fruth, A., Tietze, E. and Böhme, G. (1995) Verotoxinogenic Citrobacter freundii Associated with Severe Gastroenteritis and 
Cases of Haemolytic Uraemic Syndrome in a Nursery School: Green Butter as the Infection Source. Epidemiology \& Infection, 114, 441-450. https://doi.org/10.1017/S0950268800052158

[6] Patterson, R.H., Banister, G.B. and Knight, V. (1952) Chromobacterial Infection in Man. AMA Archives of Internal Medicine, 90, 79-86.

https://doi.org/10.1001/archinte.1952.00240070085008

[7] Chen, H.C., Kung, H.F., Chen, W.C., Lin, W.F., Hwang, D.F., Lee, Y.C. and Tsai, Y.H. (2008) Determination of Histamine and Histamine-Forming Bacteria in Tuna Dumpling Implicated in a Food-Borne Poisoning. Food Chemistry, 106, 612-618. https://doi.org/10.1016/j.foodchem.2007.06.020

[8] Tsai, Y.H., Lin, C.Y., Chang, S.C., Chen, H.C., Kung, H.F., Wei, C.I. and Hwang, D.F. (2005) Occurrence of Histamine and Histamine-Forming Bacteria in Salted Mackerel in Taiwan. Food Microbiology, 22, 461-467.

https://doi.org/10.1016/j.fm.2004.11.003

[9] Kim, S.H., Barros-Velázquez, J., Ben-Gigirey, B., Eun, J.B., Jun, S.H., Wei, C.I. and An, H. (2003) Identification of the Main Bacteria Contributing to Histamine Formation in Seafood to Ensure Product Safety. Food Science and Biotechnology, 12, 451-460.

[10] Naeem, A., Abbas, T., Ali, T.M. and Hasnain, A. (2016) Evaluation of Antioxidant and Antimicrobial Activities of Ethnic Culinary Herbs and Spices. Arab Gulf Journal of Scientific Research, 1 March 2016, 34.

[11] Mehboob, A. and Abbas, T. (2019) Evaluation of Microbial Quality of Street Food in Karachi City, Pakistan: An Epidemiological Study. Microbiology Research, 10, 1-7. https://doi.org/10.4081/mr.2019.7463

[12] Naeem, A., Abbas, T., Ali, T.M. and Hasnain, A. (2018) Inactivation of Food Borne Pathogens by Lipid Fractions of Culinary Condiments and Their Nutraceutical Properties. Microbiology Research, 9, 33-38. https://doi.org/10.4081/mr.2018.7465

[13] Cheikh-Rouhou, S., Besbes, S., Hentati, B., Blecker, C., Deroanne, C. and Attia, H. (2007) Nigella sativa L.: Chemical Composition and Physicochemical Characteristics of Lipid Fraction. Food Chemistry, 101, 673-681. https://doi.org/10.1016/j.foodchem.2006.02.022

[14] Boland, D.J., Brophy, J.J. and House, A.P. (1991) Eucalyptus Leaf Oils: Use, Chemistry, Distillation and Marketing. Inkata Press, Melbourne.

[15] Cimanga, K., Kambu, K., Tona, L., Apers, S., De Bruyne, T., Hermans, N., Totté, J., Pieters, L. and Vlietinck, A.J. (2002) Correlation between Chemical Composition and Antibacterial Activity of Essential Oils of Some Aromatic Medicinal Plants Growing in the Democratic Republic of Congo. Journal of Ethnopharmacology, 79, 213-220. https://doi.org/10.1016/S0378-8741(01)00384-1

[16] Farah, A., Satrani, B., Fechtal, M., Chaouch, A. and Talbi, M. (2001) Composition chimique et activités antibactérienne et antifongique des huiles essentielles extraites des feuilles d'Eucalyptus camaldulensis et de son hybride naturel (clone 583). Acta Botanica Gallica, 148, 183-190. https://doi.org/10.1080/12538078.2001.10515886

[17] Cruz, M.C., Santos, P.O., Barbosa Jr., A.M., De Mélo, D.L., Alviano, C.S., Antoniolli, A.R., Alviano, D.S. and Trindade, R.C. (2007) Antifungal Activity of Brazilian Medicinal Plants Involved in Popular Treatment of Mycoses. Journal of Ethnopharmacology, 111, 409-412. https://doi.org/10.1016/j.jep.2006.12.005

[18] Lopes-Lutz, D., Alviano, D.S., Alviano, C.S. and Kolodziejczyk, P.P. (2008) Screening of Chemical Composition, Antimicrobial and Antioxidant Activities of Artemisia Essential Oils. Phytochemistry, 69, 1732-1738. 
https://doi.org/10.1016/j.phytochem.2008.02.014

[19] Martins, S., Amorim, E.L., Sobrinho, T.J., Saraiva, A.M., Pisciottano, M.N., Aguilar, C.N., Teixeira, J.A. and Mussatto, S.I. (2013) Antibacterial Activity of Crude Methanolic Extract and Fractions Obtained from Larrea tridentata Leaves. Industrial Crops and Products, 41, 306-311. https://doi.org/10.1016/j.indcrop.2012.04.037

[20] Weerakkody, N.S., Caffin, N., Turner, M.S. and Dykes, G.A. (2010) In Vitro Antimicrobial Activity of Less-Utilized Spice and Herb Extracts against Selected Food-Borne Bacteria. Food Control, 21, 1408-1414.

https://doi.org/10.1016/j.foodcont.2010.04.014

[21] Han, J., Weng, X. and Bi, K. (2008) Antioxidants from a Chinese Medicinal Herb-Lithospermum erythrorhizon. Food Chemistry, 106, 2-10.

https://doi.org/10.1016/j.foodchem.2007.01.031

[22] Rhayour, K., Bouchikhi, T., Tantaoui-Elaraki, A., Sendide, K. and Remmal, A. (2003) The Mechanism of Bactericidal Action of Oregano and Clove Essential Oils and of Their Phenolic Major Components on Escherichia coli and Bacillus subtilis. Journal of Essential Oil Research, 15, 356-362. https://doi.org/10.1080/10412905.2003.9698611

[23] Moussaoui, F. and Alaoui, T. (2016) Evaluation of Antibacterial Activity and Synergistic Effect between Antibiotic and the Essential Oils of Some Medicinal Plants. Asian Pacific Journal of Tropical Biomedicine, 6, 32-37. https://doi.org/10.1016/j.apjtb.2015.09.024

[24] Toroglu, S. (2007) In Vitro Antimicrobial Activity and Antagonistic Effect of Essential Oils from Plant Species. Journal of Environmental Biology, 28, 551-559.

[25] Saklani, S. and Chandra, S. (2011) Antimicrobial Activity, Nutritional Profile and Quantitative Study of Different Fractions of Ficus palmata. International Research Journal of Plant Science, 2, 332-337.

[26] Valgas, C., Souza, S.M., Smânia, E.F. and Smânia Jr., A. (2007) Screening Methods to Determine Antibacterial Activity of Natural Products. Brazilian Journal of Microbiology, 38, 369-380. https://doi.org/10.1590/S1517-83822007000200034

[27] Chorghade, M.S. (2007) Drug Discovery and Development, Volume 2: Drug Development. John Wiley \& Sons, Hoboken. https://doi.org/10.1002/0470085223

[28] Abd El-Kalek, H.H. and Mohamed, E.A. (2012) Synergistic Effect of Certain Medicinal Plants and Amoxicillin against Some Clinical Isolates of Methicillin-Resistant Staphylococcus aureus (MRSA). International Journal of Pharmaceutical Applications, 3, 387-398.

[29] Joung, H., Kwon, D.Y., Choi, J.G., Shin, D.Y., Chun, S.S., Yu, Y.B. and Shin, D.W. (2010) Antibacterial and Synergistic Effects of Smallanthus sonchifolius Leaf Extracts against Methicillin-Resistant Staphylococcus aureus under Light Intensity. Journal of Natural Medicines, 64, 212-215. https://doi.org/10.1007/s11418-010-0388-7

[30] Tiwari, R.P., Bharti, S.K., Kaur, H.D., Dikshit, R.P. and Hoondal, G.S. (2005) Synergistic Antimicrobial Activity of Tea \& Antibiotics. Indian Journal of Medical Research, 122, 80-84.

[31] Efferth, T. and Koch, E. (2011) Complex Interactions between Phytochemicals. The Multi-Target Therapeutic Concept of Phytotherapy. Current Drug Targets, 12, 122-132. https://doi.org/10.2174/138945011793591626

[32] Enyiukwu, D.N., Awurum, A.N., Ononuju, C.C. and Nwaneri, J.A. (2014) Significance of Characterization of Secondary Metabolites from Extracts of Higher Plants in Plant Disease Management. International Journal of Advance Agricultural Re- 
search, 2, 8-28.

[33] Teethaisong, Y., Autarkool, N., Sirichaiwetchakoon, K., Krubphachaya, P., Kupittayanant, S. and Eumkeb, G. (2014) Synergistic Activity and Mechanism of Action of Stephania suberosa Forman Extract and Ampicillin Combination against Ampicillin-Resistant Staphylococcus aureus. Journal of Biomedical Science, 21, 90. https://doi.org/10.1186/s12929-014-0090-2

[34] Wang, J., Guo, J., Wu, S., Feng, H., Sun, S., Pan, J., Zhang, J. and Beebe, S.J. (2012) Synergistic Effects of Nanosecond Pulsed Electric Fields Combined with Low Concentration of Gemcitabine on Human Oral Squamous Cell Carcinoma in Vitro. PLoS ONE, 7, e43213. https://doi.org/10.1371/journal.pone.0043213

[35] Wagner, H. and Ulrich-Merzenich, G. (2009) Synergy Research: Approaching a New Generation of Phytopharmaceuticals. Phytomedicine, 16, 97-110.

https://doi.org/10.1016/j.phymed.2008.12.018. 